\title{
Analysis of Allelic Differentiation and Prediction of Suitable Parents among Brassica juncea L. Genotypes using Microsatellite Markers
}

\author{
Mir Ahmad Habib, Manmohan Sharma, Punya* , R.K. Salgotra and Usha Kiran
}

School of Biotechnology, SKUAST-J, Chatha, Jammu (J\&K), India

*Corresponding author

\section{Keywords \\ Brassica juncea L. genotypes, Alleles, SSRs, Genetic variability \\ Article Info \\ Accepted: \\ 24 May 2019 \\ Available Online: \\ 10 June 2019}

\begin{abstract}
A B S T R A C T
Information on allelic differentiation is very important to elucidate the nature and extent of divergence among Brassica juncea genotypes. In present study 20 Brassica juncea L. genotypes generated 79 polymorphic alleles from 15 SSR primer pairs with an average of 5.26 alleles per locus. The polymorphism percentage was recorded to be the maximum in the case of the primer Ni4- D04 (80\%) and the minimum in the case of 3 different primers namely A06-20686249, Ni3-D03 and A05-20242013 (33.3\%). The polymorphism information content (PIC) values ranged from 0.41 (A01-13393871) to 0.94 (A0525290881), reflecting the presence of high allelic variation. Considering the number of alleles generated by different primer pairs in conjunction with the level of polymorphism detected in the present study, the primers A04-9627743 and A04-15440685 appeared to be more informative primers. The magnitude of similarity coefficient between RH749 and Kranti (0.368) was found to be the maximum amongst pair-wise combinations of genotypes under evaluation in the present study and considered as most similar genotypes. The dendrogram generated with UPGMA cluster analysis revealed six major clusters. Genotype combinations VNIIK 405 and J/817/2, Miike Akachirimen and RH749, and VNIIK 405 and RH749 exhibited significant genetic diversity and were consider as suitable parent combinations for breeding programmes. The genotype Vardan was found to be distinct from all other groups. SSR markers utilized in the present study proved efficient in discrimination and unambiguous classification of genotypes and for identifying diverse parental combinations.
\end{abstract}

\section{Introduction}

Brassica species, commonly called as rapeseed-mustard, are the third most important oilseed crops of the world after soybean and palm. These are the second most important oilseed crops of India, next to soybean. India accounts for 19.29 percent area under rapeseed production and 11.70 percent share to the global production
(Kumarawat and Yadav, 2018). B. juncea $(2 \mathrm{n}=36$, AABB genome), an allopolyploid commonly called as Indian mustard, contributes more than 80 percent to the total rapeseed-mustard production in the country and is an important component in the oilseed sector. It is known to be more drought tolerant and shattering resistant than $B$. napus and $B$. rapa, therefore, has an enormous cultivation potential in semi-arid areas. With the 
increasing population and improving life standards, per capita oil consumption has increased tremendously. To meet out the present oil requirements, there is an urgent need to increase the yield potential of $B$. juncea through genetic interventions.

Genetic diversity in any crop species is an essential element for its improvement and adaptation to different environments. Knowledge of genetic distances between genotypes helps in selection of perspective parents for development of new high yielding varieties. These distances among parents may be attributed to their differences for number of genes and their functional relations in a given environment (Nei, 1976). Knowledge about genetic diversity in B. juncea could help breeders and geneticists to understand the structure of germplasm, predict which combinations would produce better offsprings (Hu et al., 2007), and facilitate to widen the genetic base of breeding material for selection (Qi,Yang and Zhang, 2008). Evaluation of genetic diversity and relatedness in $B$. juncea using phenotypic parameters has been previously done by many researchers (Singh et al., 2010; Alie et al., 2009). Isozyme loci have been used as markers in various genetic studies including genetic diversity in $B$. juncea (Kumar and Gupta, 1985). However, environmental factors and the developmental stages of the plant are the two limiting factors associated with these markers. Among various types of markers used for genetic diversity estimation in plants, molecular or DNA markers are more specific, proficient, precise and consistent in distinguishing closely related cultivars or species (Mishra et al., 2011). Amongst the various types of molecular markers used, microsatellite or simple sequence repeat (SSR) markers are preferred ones because of their higher reproducibility, co-dominance nature and abundance, wide distribution throughout the genome, easy storability and multi-allelic variation (Powell et al., 1996). They are highly polymorphic PCR-based markers and are expected to be very powerful in germplasm discrimination. More reliable SSR markers are now available which are present in abundance genome-wide in $\mathrm{A}$ and $\mathrm{B}$ genomes of $B$. juncea and are efficient in identification of polymorphism (Sharma et al., 2018 and Sharma et al., 2019). Keeping into consideration the potential of SSR markers in assessing the nature and extent of genetic diversity among germplasm, the present study was conducted to generate reliable information on the genetic relationship among germplasm of Brassica juncea and to identify suitable parents for breeding programme.

\section{Materials and Methods}

The molecular characterization of twenty five Brassica juncea genotypes, belonging to both Indian and European genepools (Table 1), was carried out at the Plant Genomics Laboratory of School of Biotechnology, Sher-e-Kashmir University of Agricultural Sciences \& Technology of Jammu, Chatha during 201819. The genotypes were grown for genomic DNA extraction from young and actively growing fresh leaves using modified cetyltrimethyl-ammonium bromide (CTAB) method (Doyle and Doyle, 1990). Amplification of DNA was carried out by using a panel of 15 SSR primer pairs (Table 2 ) in total volume of $10 \mu \mathrm{l}$ containing $5.3 \mu \mathrm{l}$ of nuclease free water, $2.2 \mu \mathrm{l} 5 \mathrm{X}$ PCR buffer with $15 \mathrm{mM}\left(\mathrm{MgCl}_{2}\right), 0.3 \mu \mathrm{l}$ of $2.5 \mathrm{mM} / \mu 1$ dNTP, $0.5 \mu$ of each forward and reverse primers, $5 \mathrm{U}$ of $\mathrm{Taq}$ polymerase. Amplification cycle comprised of initial denaturation for $5 \mathrm{~min}$ at $94^{\circ} \mathrm{C} ; 30$ cycles of $94^{0} \mathrm{C}$ for $1 \mathrm{~min}$, annealing at $58{ }^{\circ} \mathrm{C}$ for $1 \mathrm{~min}$ and extension at $72^{\circ} \mathrm{C}$ for 2 min.; followed by a final extension at $72{ }^{\circ} \mathrm{C}$ for $7 \mathrm{~min}$. in Master Cycler Gradient (Eppendorf). The products of amplification were stored at $4^{0} \mathrm{C}$ and resolved 
by electrophoresis in horizontal agarose gel system at $110 \mathrm{~V}$ for $1 \mathrm{~h} 30 \mathrm{~min}$. on $2 \%$ agarose gel stained with ethidium bromide $(10 \mathrm{mg} / \mathrm{ml})$ using $1 \mathrm{X}$ TBE buffer. The amplified products were visualized under gel documentation system and the size of amplicons was estimated with the help of 100bp ladder (Fermentas).

Allelic differentiation was determined on the basis of presence and absence of bands in different genotypes and data recorded in this respect were entered into binary matrix as discrete variables and this data matrix was subjected to further analysis for calculating, total alleles, number of alleles per locus, number of unique and shared alleles. The polymorphism information content (PIC) value was calculated for each SSR marker measuring the diversity of alleles at one locus by the formula:

$\mathrm{PIC}=1-\sum \mathrm{f}_{\mathrm{i}}{ }^{2}$

Where, $f_{i}$ is the frequency of ith allele (Smith et al., 1997).

The information regarding informativeness of the marker was obtained by computing the polymorphism percent as follows:

$\mathrm{PP}=($ Number of unique alleles/Total number of alleles) x 100

The degree of genetic similarity is the level of character similarity of the genotypes and is estimated from the number of allele data using the Jaccard coefficient (Rohlf, 2000) with the formula:

$$
\mathrm{GS}=\frac{m}{(n+u)}
$$

Where, $\mathrm{m}=$ the number of DNA (allele) bands of the same position; $\mathrm{n}=$ total DNA band; $u=$ the number of bands (alleles) of DNA that are not equal in position.
The dendogram based on similarity indices was obtained by un-weighted pair-group method using arithmetic mean (UPGMA). Analysis was performed with the help of NTSYS-pc software (Rohlf, 1997). The nature of differentiation and diversity among brassica genotypes under evaluation in the present investigation was assessed by identifying the clusters at appropriate phenon levels. Principal component analysis is another multivariate approach utilized in present study to estimate the extent of genetic variability among Brassica genotypes evaluated

\section{Results and Discussion}

Amplification pattern of targeted genomic region of twenty genotypes of Brassica juncea using fifteen SSR markers revealed that there is significantly higher level of allelic differentiation among them. Genetic diversity assessment at molecular level was done by the presence or absence, relative position and size of bands (Figure 1). The efficiency of primer pairs was determined by calculating the number of allelic variants and the occurrence of unique allelic variant (Chen et al., 2011 and Chandra et al., 2013). Moreover, exclusive bands proved valuable to distinguish the genotypes at the molecular level without using field data (Sahu et al., 2012 and Vinu et al., 2013)

Altogether 79 alleles were obtained from 15 SSR primer pairs with an average of 5.26 alleles per locus. The number of alleles per locus ranged from 3 in the case of primer A05-20242013 to 8 in the case of Ni4-G08 with a range between 80 bp to 295bp (Table $3)$. The polymorphism percent revealed in the form of percentage of unique alleles was recorded to be the maximum in the case of the primer Ni4- D04 (80\%) and the minimum in the case of 3 different primers namely A0620686249, Ni3-D03, \& A05-20242013 
$(33.3 \%)$ with an average value of 44.9 percent. Remarkably greater magnitude of polymorphism percentage was obtained in the cases of primers A01-13393871, Ni2-F11, Ni2-D12, A04-9627743, Ni4-D04, A0415440685 and A07-7758930. The results obtained in this study are comparable to those reported earlier (Salazar et al., 2006; Abdelmigid, 2012; Ali et al., 2007 and Khan et al., 2011). The polymorphism information content (PIC) demonstrated the informativeness of primer pairs and their potential to detect differences among genotypes based on genetic differences. In the present study, PIC values ranged from 0.41 (A01-13393871) to 0.94 (A05-25290881) with mean of 0.73 which matched the findings of other workers (Shi et al.,2014; Ali et al., 2019; Avtar et al., 2016), reflecting the presence of high allelic variation. Significantly greater magnitude of PIC value was obtained in the case of primers A0218870790, Ni3-D03, Ni4-G08, A0322221630, A04-9627743, Ni4-D04, A0415440685 and A05-20242013. Among the primer pairs having higher PIC values, primers A02-18870790, Ni2-D12, Ni3-D03, Ni4-G08, A04-9627743 and A04-15440685 generated considerably greater number of allelic variants per primer due to variation in the length of simple sequence repeats based amplified products as a consequence of amplification of the simple sequence repeats flanked by these primer pairs. Further, the primer pairs A04-9627743 and A0415440685 detected considerably greater percentage of unique alleles amongst these eight primer pairs which had higher polymorphism information content and generated greater number of alleles. Considering the number of alleles generated by different primer pairs in conjunction with the level of polymorphism detected in the present study, the primers A04-9627743 and A04-15440685 appeared to be more informative primers.
The estimates of similarity coefficients amongst Brassica genotypes, which were computed by a comparison on the basis of presence and absence of the amplified products generated with fifteen primer pairs, ranged from zero to 0.368 . The magnitude of similarity coefficient between RH749 and Kranti (0.368) was found to be the maximum amongst pair-wise combinations of genotypes under evaluation in the present study and considered as the most similar genotypes. This was followed by remarkably higher magnitude of similarity coefficient between Yanagawa Shirokukiand and Commercial Brown Mustard, Yanagawa Shirokuki and Vardann; and Kranti and RSPR-69. However, the magnitude of similarity coefficient between VIIMK 405 and J/817/2, Miike Akachirimen and RH749, VNIIK 405 and RH749 was equal to zero. The results revealed ample diversity at the molecular level amongst the twenty genotypes under evaluation in the present study. Considering broad classification of Brassica genotypes as revealed by dendrogram, genotypes subjected to molecular characterization in the present study were classified into six clusters (Figure 2). Out of six clusters, three clusters, namely, the cluster II, cluster III and cluster VI were mono-genotypic consisting of SB-12-P4, VNIIMK 351 and Vardan respectively. Cluster I was di-genotypic comprising Neosypajusca 2 and, J/817/2, and cluster IV was tri-genotypic consisting of RH749, RSPR-69, Kranti whereas cluster V was multi-genotypic having Miike Skorospelka, J807/1/6, VNIIMK 405, Zeltoseminaja 230, Pusa Mehak, Primus, Skorospelka, IB1436, Raya, Brown Mustard and Yanagawa Shirokuki. Cluster IV and cluster V were further subdivided into sub-clusters, accommodating only the genotypes with increasingly similar pattern of marker genotyping. The genotype Vardan was found to be distinct from all other groups, as it was accommodated into a separate cluster 
showing more divergence. Thus, present study, depicted that genotypes which were genetically similar were grouped together and explained the relationship between these genotypes. Genetic variation estimated among $B$. juncea genotypes evaluated will be further helpful in developing and planning breeding strategies for developing high yielding varieties and hybrids.

Principal component analysis (PCA) reveals the major contributor of the total variability at each distint point. Results of PCA along the two principal axes in two diamensional plots of fifteen SSR primers dependent genetic profile are depicted in Figure 3. The first principal components showed Eigen value more than one and cumulatively explained 13.3 percent variability. Twenty Brassica juncea genotypes studied here exhibited significant genetic diversity; the highest being between genotypes VNIIK 405 and J/817/2, Miike Akachirimen and RH749; and VNIIK 405 and RH749, while minimum genetic diversity between RH749 and Kranti was reflected. The most important attribute of SSR marker is their high level of allelic variation, making them valuable and informative genetic markers (Fayyaz et al., 2014; Hassan et al., 2006 and Subaran et al., 2017). The results of this investigation clearly indicated that utilization of fifteen SSR primer pairs in the analysis of Brassica juncea genotypes revealed a remarkably higher level of genetic polymorphism, which allowed unique genotyping of Brassica juncea included in the analysis.

Table.1 Brassica juncea genotypes used in the study

\begin{tabular}{|l|l|l|}
\hline $\begin{array}{l}\text { Sl. } \\
\text { No. }\end{array}$ & Genotypes & Country \\
\hline 1 & J/817/2 & United Kingdom \\
\hline 2 & Neosypajuscajasia 2 & Russia Federation \\
\hline 3 & Miike Akachirimen & Japan \\
\hline 4 & VNIIMK 351 & Russia Federation \\
\hline 5 & Skorospelka & Russia Federation \\
\hline 6 & Skorospelka 2 & Russia Federation \\
\hline 7 & Pusa Mehak & India \\
\hline 8 & J807/1/6 & United Kingdom \\
\hline 9 & VNIIMK 405 & Russia \\
\hline 10 & Primus & Canada \\
\hline 11 & IB-1436 & India \\
\hline 12 & SB-12-P4 & India \\
\hline 13 & Zeltosemiannaja 230 & Russia \\
\hline 14 & Raya (L.23) & Pakistan \\
\hline 15 & Vardan & India \\
\hline 16 & Commercial Brown Mustard & Canada \\
\hline 17 & Yanagawa Shirokuki & Japan \\
\hline 18 & RSPR-69 & India \\
\hline 19 & Kranti & India \\
\hline 20 & RH749 & India \\
\hline
\end{tabular}


Table.2 SSR primers used for analysing genetic diversity in Brassica juncea germplasm

\begin{tabular}{|c|c|c|}
\hline Sl.no. & Primers & Sequences \\
\hline 1 & A04-9627743 & $\begin{array}{l}\text { F 5'ATGGAATCTGCTCATCTCAC3' } \\
\text { R 3'TAAGCTGCAATGATCAAAGAT5' }\end{array}$ \\
\hline 2 & A04-15440685 & $\begin{array}{l}\text { F 5'TTTGAACGATACACAACAACA3' } \\
\text { R 3'GTTGGTCCACGAGTAAAAGAT5' }\end{array}$ \\
\hline 3 & A05-20242013 & $\begin{array}{l}\text { F 5'AGAAGCTTTTTCTCTTGTTGC3' } \\
\text { R 3’TGATGTAAGAGCGTGAAAGAT5' }\end{array}$ \\
\hline 4 & A05-25290881 & $\begin{array}{l}\text { F 5'ATAAAGATTTGATGGGAGGAG3' } \\
\text { R 3'GGTGGAGGAGGATAGTTGTAG5' }\end{array}$ \\
\hline 5 & A07-20686249 & $\begin{array}{l}\text { F 5'AGGAAAAGACTGGAAAGTGTC3' } \\
\text { R 3'CTTCTGCTCCTCTTGTTGTTA5' }\end{array}$ \\
\hline 6 & A01-13393871 & $\begin{array}{l}\text { F 5'CCGTTTTTATGTCACAAATCT3' } \\
\text { R 3'AAACAAAACGAACTTTGTCAG5' }\end{array}$ \\
\hline 7 & A02-188870790 & $\begin{array}{l}\text { F 5'TACACCGTCTGATTCCATCT3' } \\
\text { R 3'GCCTGACTGCTGCTACTAAC5' }\end{array}$ \\
\hline 8 & AO3-3174449 & $\begin{array}{l}\text { F 5'AAAGAAGAGCTTTGAAGAGGA3' } \\
\text { R 3'TTGATTCACAACACACATACC5' }\end{array}$ \\
\hline 9 & AO7-7758930 & $\begin{array}{l}\text { F 5'AGGTGATATGCTCAAACACAC3' } \\
\text { R 3'TACGGTGAAAAATCGCTAATA5' }\end{array}$ \\
\hline 10 & AO3-22221630 & $\begin{array}{l}\text { F5'ATCGTCTCTTTCGTCTTGTCT3' } \\
\text { R 3'CGTAAAACTGAAACCATTCAC5' }\end{array}$ \\
\hline 11 & Ni2-F11 & $\begin{array}{l}\text { F 5'AAAGGGTTTCAATTTCACGC3' } \\
\text { R 3'GGGAAACATACTCACCACGC5' }\end{array}$ \\
\hline 12 & Ni2-D12 & $\begin{array}{l}\text { F 5'GAGATGAGGATTTGCTTTTGC3' } \\
\text { R3'ACAGTATGAGAGAGAGAGAGAGAG5' }\end{array}$ \\
\hline 13 & Ni3-D03 & $\begin{array}{l}\text { F 5'ACCGGAGACGAAACTACCG3' } \\
\text { R 3'CCTCTTCGACGTTTTTGGTG5' }\end{array}$ \\
\hline 14 & Ni4-G08 & $\begin{array}{l}\text { F 5'ATTTGACGGACTCCTCTTGC3' } \\
\text { R3'CACTTGGTAACTCTATGGATGCC5' }\end{array}$ \\
\hline 15 & Ni4-D04 & $\begin{array}{l}\text { F 5'TTTAAAGTGTGTTTCACAAACTGG3' } \\
\text { R 3'GAGTTCACAGGGGCTACAGG5' }\end{array}$ \\
\hline
\end{tabular}


Table.3 Analysis of allelic differentiation in Brassica juncea genotypes based on the amplification of SSR markers

\begin{tabular}{|l|l|c|c|c|c|}
\hline Sl. No. & Primer & $\begin{array}{c}\text { No. of } \\
\text { alleles }\end{array}$ & $\begin{array}{c}\text { Allele Size } \\
\text { (bp) }\end{array}$ & PP & PIC \\
\hline 1 & A01-13393871 & 4 & $135-160$ & 50 & 0.41 \\
\hline 2 & A02-18870790 & 7 & $160-198$ & 42.8 & 0.807 \\
\hline 3 & A05-25290881 & 4 & $125-150$ & 40 & 0.94 \\
\hline 4 & A06-20686249 & 5 & $160-175$ & 33.3 & 0.62 \\
\hline 5 & Ni2-F11 & 4 & $150-170$ & 50 & 0.53 \\
\hline 6 & Ni2-D12 & 5 & $145-175$ & 60 & 0.73 \\
\hline 7 & Ni3-D03 & 6 & $110-125$ & 33.3 & 0.76 \\
\hline 8 & Ni4-G08 & 8 & $80-110$ & 37 & 0.80 \\
\hline 9 & A03-22221630 & 5 & $160-175$ & 40 & 0.735 \\
\hline 10 & A03-3174449 & 5 & $170-190$ & 40 & 0.72 \\
\hline 11 & A07-7758930 & 5 & $135-160$ & 60 & 0.63 \\
\hline 12 & A04-9627743 & 6 & $195-220$ & 50 & 0.75 \\
\hline 13 & Ni4-D04 & 5 & $270-295$ & 80 & 0.83 \\
\hline 14 & A04-15440685 & 7 & $170-192$ & 57.14 & 0.91 \\
\hline 15 & A05-20242013 & 3 & $170-160$ & 33.3 & 0.86 \\
\hline
\end{tabular}

Fig.1

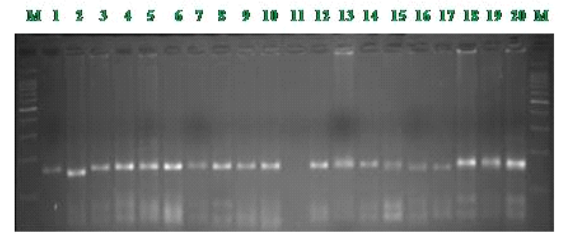

Prinmer_A 2-18570796

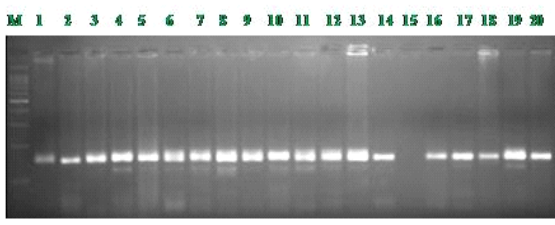

Prinear : A $03-22221630$

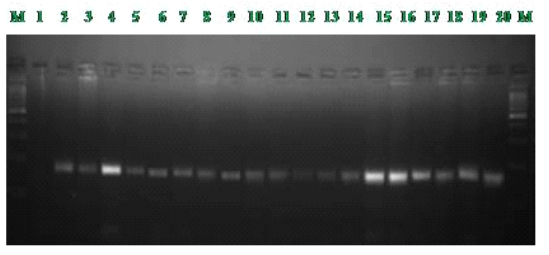

Prinuer : At3-3174449

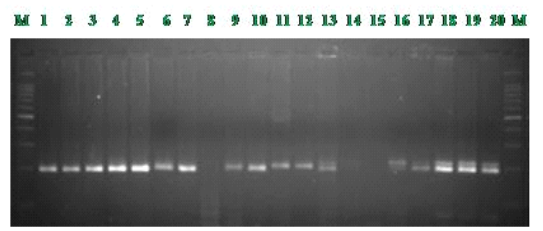

Prineer : Ni2-17II

\begin{tabular}{|c|c|c|c|c|c|c|c|}
\hline S1. No. & Genotypes & SI. No. & genotypes & SL. No. & genotypes & SI. No. & genotypes \\
\hline 1. & $\mathrm{~J} / 817 / 2$ & 6. & Skorospelka 2 & 11. & IB-1436 & 16. & Commercial Brown Mnstard \\
\hline 2 & Neosypajusxijain 2 & 7. & Pusa Mehak & 12 & SB-12-P4 & 17. & Yanagrwa Shirokuki \\
\hline 3. & Mike Akachirimen & 8. & 5807/1/6 & 13. & Zeltosemiannaja 230 & 18. & RSPR-69 \\
\hline 4. & VNIIMK 351 & 9 & VNIIMK 405 & 14. & Raya (L.23) & 19. & Kranti \\
\hline 5. & Skorospelka & 10. & Primus & 15. & Vardan & 20. & RH749 \\
\hline
\end{tabular}

Figl. Primer pair dependent anplifiration of region of DNA extrated from leaves at seedling stage in different brascira genetypes. 
Fig.2 Dendrogram based on Jaccard similarity coefficients for fifteen SSR primer pairs among 20 Brassica juncea genotypes

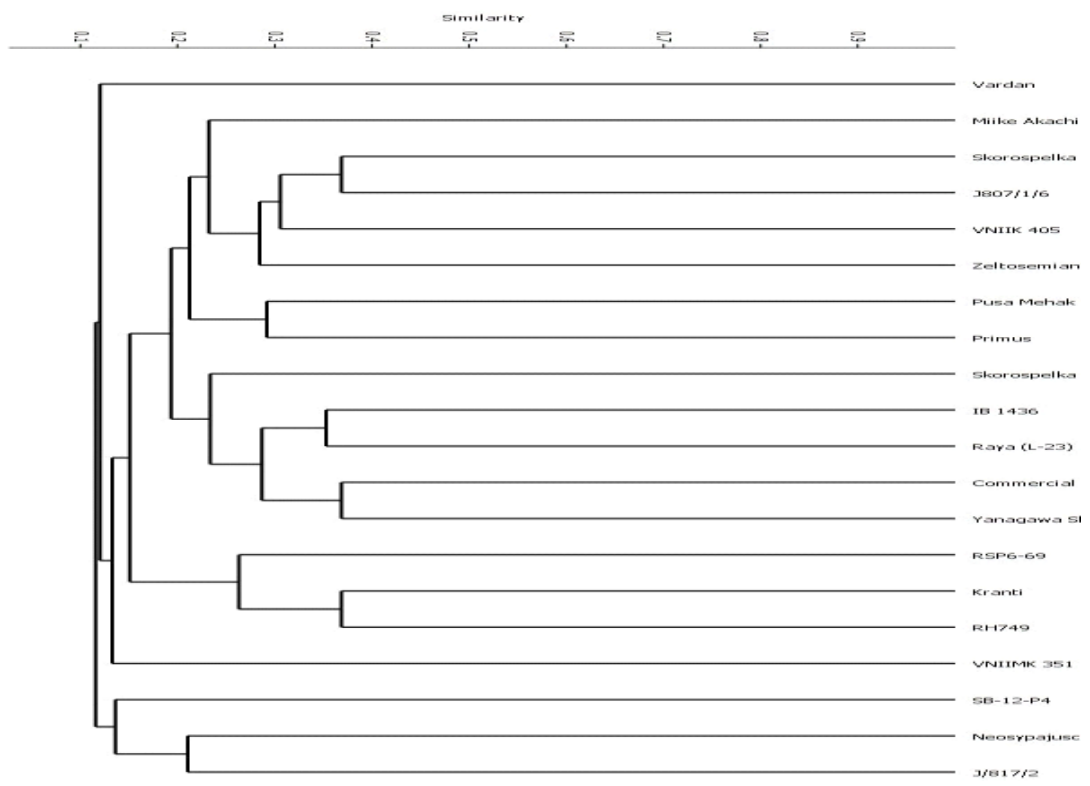

Fig.3 Principal component analysis based on fifteen SSR primer pairs among of twenty Brassica juncea genotypes

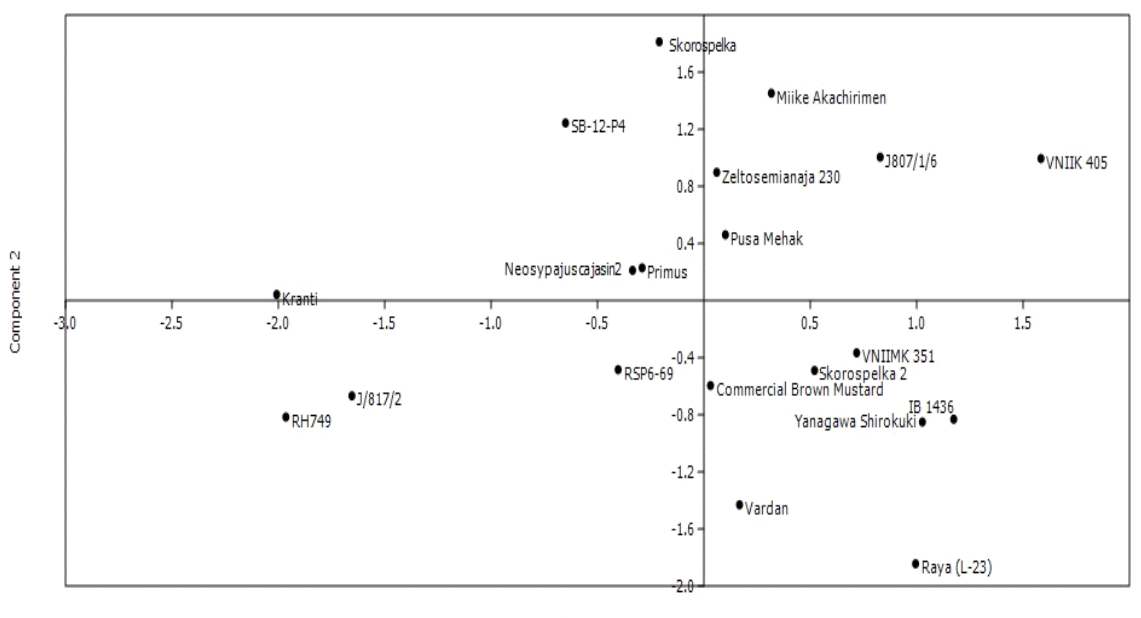

Component 1

Selection of appropriate parents to be used in any crop improvement programme is one of the main decisions taken by plant breeders, which facilitates the exploitation of minimum genetic similarity and production of superior recombinant genotypes. Based on the values of similarity coefficients observed, parental combinations identified included VNIIK 405 
and J/817/2, Miike Akachirimen and RH749, and VNIIK 405 and RH749 which are predicted to yield better $\mathrm{F}_{1 \mathrm{~s}}$ and recombinants. It has been reported previously that SSR is an important tool for germplasm characterization in a variety of crops, including oilseed Brassica (Saal et al., 2001). A similar result regarding effectiveness of SSR markers in monitoring genetic diversity have also been reported by Hopkins et al., (2006) and Fu and Gugel, (2010). Thus, SSR markers utilized in the present study were founf efficient in discrimination and unambiguous classification of genotypes and for identifying diverse parental combinations to create segregating progenies with maximum genetic variability for further selection.

\section{Acknowledgements}

The authors acknowledge Department of Biotechnology, New-Delhi for financial support and School of Biotechnology, SKUAST-Jammu for providing facilitied to carry out the work.

\section{References}

Abdelmigid, H.M., 2012. Efficiency of random amplified polymorphic DNA (RAPD) and Inter-simple sequence repeats (ISSR) markers for genotype fingerprinting and genetic diversity studies in canola (Brassica napus). African J. Biotech. 11: 6409-6419.

Ali, W., I. Munir, M. A. Ahmad, W. Muhammad, N. Ahmed, A.S. Durrishahwar, and Swati, Z.A. 2007. Molecular characterization of some local and exotic Brassica juncea germplasm. African J. Biotech. 6: 1634-1638.

Alie, F. A., T. Singh, Tariq and Sharma, P.K. 2009. Genetic diversity analysis in Indian mustard [Brassica juncea (L.) czern \& coss]. Progr. Agri. Internl. J.
9: 50-53.

Avtar, R., B. Rani, M. Jattan, M.N. Kumari and Rani, A. 2016. Genetic diversity analysis among elite gene pool of Indian mustard using SSR markers and phenotypic variations. The Bioscan. 11(4): 3035-3044.

Chandra, V., U. Pant, R. Bhajan and Singh, A.K. 2013. Studies on genetic diversity among Alternaria blight Tolerant Indian mustard genotypes using SSR markers. The Bioscan. 8(4):1431-1435.

Chen, F. B., K.C. Yang, G. F. Zhou, Y. H. Fan, Z.Y. Zhang, J. J. Shen, H. Zhang, and Jiang, L. L. 2011. Analysis of Heterosis, Combining Ability and Genetic Diversity in Tuber Mustard (Brassica juncea var. tumida Tsen \& Lee) Inbred Lines Based on SSR Markers and Combining Ability Estimates. Philipp agric scientist ISSN 0031-7454. 94(2): 124-131.

Doyle, J.J., and Doyle, J.L. 1990. Isolation of plant DNA from fresh tissue. Focus. 12:13-15.

Fayyaz, L., Farhatullah, M. A. Rabbani., S. Iqbal., M. Kanwal and Nawaz, I. 2014. Genetic diversity analysis of Brassica napus/Brassica compestris progenies using microsatellite markers. Pakistan Journal of Botany. 46(3):779-787.

$\mathrm{Fu}$, Y. B. and Gugel, R. K. 2010. Genetic Diversity of Canadian elite summer rape (B. napus L.) Cultivars from the pre to post canola quality era. Can. J. Plant Sci. 90: 23-33.

Hasan, M., F. Seyis, A. G. Badani, J. Pons-Ku hnemann, W. Friedt, W. Lu hs and Snowdon, R.J. 2006. Analysis of genetic diversity in the Brassica napus L. gene pool using SSR markers. Genetic Resources and Crop Evolution, 53: 793-802.DOI $10.1007 / \mathrm{s} 10722-004-5541-2$ 
Hopkins, C., R. Mogg, N. Gororo, P. Salisbury, W. Burton, C. Love , G. Spangenberg, D. Edwards, and Batley, J. 2006. An Assessment of Genetic Diversity within and between Brassica napus and Brassica juncea lines from International Germplasm Collections. Proc. Joint Meeting $14^{\text {th }}$ Crucifer Genetics Workshop 115 and $4^{\text {th }}$ ISHS Symposium on Brassicas. Acta. Hort. 706: 115-119.

Hu, S., C. Yu, H. Zhao, G. Sun, S. Zhao, M. Vyvadilova and Kucera, V. 2007. Genetic diversity of Brassica napus L. Germplasm from China and Europe assessed by some agronomically important characters. Euphytica 154: 916.

Khan, W.M., I. Munir, Farhatullah, M. Arif, A. Iqbal, I. Ali, D. Ahmad, M. Ahmad, A. Mian, J. Bakht, Inamullah and Swati, Z. A. 2011. Assessment of genetic diversity of Brassica juncea germplasm using Randomly Amplified Polymorphic DNA (RAPD) markers. African J. Biotech. 10:36543658.

Kumar, R., and Gupta, V.P. 1985. Isozyme studies in Indian mustard (Brassica juncea L.). Theor Appl. Genet. 69: 14.

Kumarawat, M. and Yadav, M. 2018. Trends in area, production and yield of mustard crop in Bharatpur region of Rajasthan. Int. J. of Eng. Dev Res. 6(1): 315-321.

Mishra, M. K., N. Suresh, A.M. Bhat, N. Suryaprakash, S. S. Kumar, A. Kumar and Jayarama 2011. Genetic molecular analysis of Coffea arabica (Rubiaceae) hybrids using SRAP markers. Rev. Biol. Trop. 59: 607617.

Nei, M., 1976. Analysis of gene diversity in subdivided populations. Pro Nat. Acad. Sci. USA 70: 3321-3323.
Powell, W., G. C. Machray and Provan, J. 1996. Polymorphism revealed by simple sequence repeats. Trends Plant. Sci. 1: 215-222.

Qi, X., J. Yang and Zhang, M. 2008. AFLP based genetic diversity assessment among Chinese vegetable mustards (Brassica juncea (L.) Czern.). Genet. Resour Crop Evol. 55: 705-711.

Raza, A., S. S. Mehmood, F. Ashraf and Khan, R. S. A. 2019. Genetic Diversity Analysis of Brassica Species Using PCR-Based SSR Markers. Gesunde Pflanzen, 71(1): 17.

Rohlf, F. J. 2000. NTSYSpc Numerical Taxonomy and Multivariate Analysis System Version 2.1. Applied Biostatistics Inc.

Saal, B., J. Plieske, J. Hu, C. F. Quiros and Struss, D. (2001) Microsatellite markers for genome analysis in Brassica II. Assignment of rapeseed microsatellite to the A genomes and genetic mapping in Brassica oleracea (L.) Theor Appl. Genet. 102:695-699.

Sahu, P., D. Khare, N. Tripathi, A. N. Shrivastava and Saini, N. 2012. Molecular screening for disease resistance in soybean. J. Food Leg. 25(3):200- 205

Salazar, B., H. Laurentin, M. Davila and Castillo, M. A. 2006. Reliability of the RAPD technique for germplasm analysis of sesame (Sesamum indicum L.) from Venezuela. Interciencia 31:456-460.

Sharma, D., M. Sharma, R. K. Salgotra, S. Hangloo, S. K. Gupta and Punya 2019 Screening of microsatellite markers for establishing parental polymorphism in Brassica juncea. Indian Res. J. Gene. \& Biotech. 11(1): 18-24.

Sharma, M., Punya, R. K. Salgotra, S. K. Gupta, S. K. Rai, U. Kiran, and Singh 
A. 2018. Molecular profiling of Brassica juneca genotypes using SSR marker derived polymorphism in Indian mustard. India Res. J. Gene. \& Biotech. 10(3): 342-346.

Shi, J., S. Huang, J. Zhan, J. Yu, X. Wang, W. Hua, S. Liu, G. Liu and Wang $\mathrm{H}$. 2014. Genome-wide microsatellite characterization and marker development in the sequenced Brassica crop species. DNA Res. 21:53-68.

Singh, D., R. K. Arya, N. Chandra, R. Niwas and Salisbury, P. 2010. Genetic diversity studies in relation to seed yield and its component traits in Indian mustard (Brassica juncea L. Czern \& Coss.). J. Oil. Brass. 1:19-22.

Singh, S., V.V. Singh, S. Ambawat, M. Dubey and Singh, D. 2017. Screening and Estimation of Allelic Differentiation in Indian mustard Using SSR Markers for Background Selection Int. J. Curr. Microbiol. App. Sci, 6(9): 2506-2516

Smith, J.S.C, E.C.I. Chin, H. Shu, O.S. Smith and Wall S. J. 1997. An evaluation of utility of SSR loci as molecular markers in maize (Zea mays L.): comparisons with data from RFLPs and pedigree, Theor Appl Genet 95:163-173.

Vinu, V., M. Singh, S. Vasudev, D. K. Yadava, S. Kumar, S. Naresh, S. R. Bhat and Prabhu K.V. 2013. Assessment of genetic diversity in Brassica juncea (Brassicaceae) genotypes using phenotypic differences and SSR markers. Rev. Biol. Trop. 61(4): 1919-1934.

\section{How to cite this article:}

Ahmad Habib, Mir, Manmohan Sharma, Punya, R.K. Salgotra and Usha Kiran. 2019. Analysis of Allelic Differentiation and Prediction of Suitable Parents among Brassica juncea L. Genotypes using Microsatellite Markers. Int.J.Curr.Microbiol.App.Sci. 8(06): 3071-3081. doi: https://doi.org/10.20546/ijcmas.2019.806.366 